crystals. It was all about the nature of proteins and viruses. Bragg:

"How do protein molecules get folded? Can no one make a protein?"

Bernal:

"It looks as if all proteins are made by others inside the cells."

Bragg:

"But if one protein must always come from another, how did the first one get there?"

Bernal's answer avoids this paradox.

"One big step towards finding out is getting the structure of proteins and viruses. It's really the problem of the origin of life."

No inkling yet about the role of nucleic acids. Bernal had been Bragg's research student, and Bragg may have had him in mind when he wrote:

"A good research student is like a fire which needs but a match to start it."

Quotations such as this one make the book delightful reading.

I was intrigued by the similarities between father and son. They had both read mathematics, but neither was a theoretician at heart, and they solved scientific puzzles in a concrete, visual fashion. The father complained of Planck not bothering to think about the physical nature of the quantum and to the son quarks had no appeal. To them a structure solved was like an artist's vision, to be described in words of poetic imagery. They felt more at ease with children than adults and preferred to deal with things rather than people. They were no match for politicians: the father was taken for a ride by the higher civil servants when he demanded that science should have a stronger voice in the conduct of the war; the son was helpless among the Byzantine complexities of University politics. The father's faith in God and the goodness of science marks him out as a man of the last century rather than of this one; the son avoided ultimate questions and tended his garden.

What would the reader gain from this book? Much enjoyment; the realisation that success in science can be combined with devotion to human values, and that occasionally the great can also be good and true.

M. F. Perutz is Chairman of the Governing Board of the MRC Laboratory of Molecular Biology, Cambridge, UK.

\section{DNA inconstancy}

Endopolyploidy and Polyteny in Differentiation and Evolution. By W. Nagl. Pp. 283. (Elsevier/North-Holland: Amsterdam, New York and Oxford, 1978.) \$54.50; Dfl. 125 .

As indicated by its title, this book is concerned with the relationships between two of the central issues in biology-namely, differentiation and evolution. The thread that connects the two, as seen by the author, is the occurrence of DNA variation as an important aspect of both. Evolution has been accompanied by remarkable shifts in the amount, and in the organisation, of basic genomal DNA in different species. Moreover, in very many Orders of animals and plants, there occurs varying degrees and types of ontogenetic elaboration of the basic genome. These are seen in their most obvious expression as polyteny and endopolyploidy, and more subtly, as amplification of certain selected regions of the genome such as the ribosomal cistrons.

To many biologists, such expressions of DNA inconstancy are mere curiosities which, though useful experimentally, serve to emphasise the rule of DNA constancy, with normal mitosis as the orthodox mechanism of DNA growth. Reading this book will do much to redress the balance for, far from being the exception and the concern of insects and bugs, DNA inconstancy is to be found universally. In fact, after reading this book one feels that the cell nucleus has such a penchant for ontogenetic elaboration that the problem becomes not how or why this occurs, which are matters discussed at length, but how species manage at all to maintain DNA constancy for the purposes of ensuring their continuation.

In all probability it is precisely the failure of species entirely to constrain the exuberance of DNA in this respect that is one of the main driving forces of the evolutionary process. In a very real sense, therefore, the study of ontogenetic DNA variation contains valuable clues to the understanding of phylogenesis and evolution. In other words, speciation and differentiation are two sides of the same coin, which is DNA variation. Along the way to making this point the book commences with a concise and up-to-date account of the organisation of the eukaryotic chromosome and continues with chapters dealing with the occurrence and characterisation of endopolyploid nuclei, the mechanism of endopolyploidisation, further mechanisms of DNA variation, control of endopolyploidisation and polytenisation, functional significance of endocycles, and, finally, evolutionary aspects.

This final chapter brings together the threads runing through the previous parts of the book in a far ranging discussion concerned with the meaning of DNA variation in evolution. Com- mencing with a tabulation of the various mechanisms of, and the terminology for, DNA variation in phylogeny and ontogeny, the author discusses the role of point mutations (adaptation and anagenesis) and of repetitive DNA (speciation and cladogenesis) in the evolutionary process. In particular he emphasises the nucleotypic effects of alterations in DNA and of genomal DNA repatterning as important mechanisms. Nucleotypic effects are considered to be explicable principally in terms of the Britten-Davidson model of gene regulation and the relationship of DNA interspersion patterns to genome size is discussed as a possible nucleotypic effect of DNA mass. Endopolyploidisation and differential DNA replications are considered as evolutionary strategies in light of the fact that, in general, these phenomena achieve their most extreme expression in species with relatively low DNA C values.

The final paragraphs of this chapter set out the author's views concerning the integration of DNA variations Juring ontogenesis and evolution summarised by what he terms the DNA optimisation model. This illustrates some possible changes in genomal size and organisation during phylogenesis and considers their possible consequences on development. This is altogether a very thought-provoking section of the book which is otherwise an extensive and important review.

Altogether there are 283 pages, of which 49 pages are of references, including the Russian and older German papers, amounting in all to over 1200 references of which 55 are to the work of the author and his colleagues. These are extensively cited and critically discussed and crossreferenced, making this not a book to be read without effort. It is well and profusely illustrated with line diagrams and half-tones, and contains many unique and informative tabulations of data collected from the numerous sources cited. There is a useful subject index and two appendices containing a glossary of terms and further guidance to the methodological literature dealing with the detection of endopolyploidy and differential DNA replication, the preparation and analysis of chromosomes, in situ hybridisation, DNA characterisation, and genome organisation analysis.

An indispensible book for the expert but aimed also at a wider readership, it should appeal to students of cytogenetics and molecular biology.

K. W. Jones

$K$. $W$. Jones is Reader in the Institute of Animal Genetics, University of Edinburgh, $U K$. 